\title{
Chloroquine Exerts Anti-metastatic Activities Under Hypoxic Conditions in Cholangiocarcinoma Cells
}

\author{
Suyanee Thongchot ${ }^{1,3}$, Watcharin Loilome ${ }^{1,3}$, Puangrat Yongvanit ${ }^{1,3}$, Hasaya \\ Dokduang ${ }^{1,3}$, Raynoo Thanan ${ }^{1,3}$, Anchalee Techasen ${ }^{2,3}$, Nisana Namwat ${ }^{1,3 *}$
}

\begin{abstract}
Intra-tumoral hypoxia is an environment that promotes tumor cell migration, angiogenesis and epithelialmesenchymal transition that accounts for a major mechanism of metastasis. Chloroquine potentially offers a new therapeutic approach with an 'old' drug for effective and safe cancer therapies, as it exerts anti-metastatic activity. We investigated the inhibitory effect of chloroquine on cholangiocarcinoma (CCA) cell migration under cobalt chloride $\left(\mathrm{CoCl}_{2}\right)$-stimulated hypoxia. We showed that chloroquine suppressed CCA cell migration under hypoxic-mimicking conditions on exposure to $100 \mu \mathrm{M} \mathrm{CoCl}_{2}$. Moreover, chloroquine stabilized the protein level of prolyl hydroxylase domain proteins (PHD-2) but reduced the levels of hypoxic responsive proteins such as hypoxia-inducible factor (HIF-1 $\alpha$ ) and vascular endothelial growth factor (VEGF). It also suppressed epithelial mesenchymal transition (EMT) by increasing the ratio of $\mathbf{E}$-cadherin to $\mathrm{N}$-cadherin under hypoxic conditions. In conclusion, chloroquine can inhibit hypoxia-stimulated metastasis via HIF-1 //VEGF/EMT which may serve as a useful additional strategy for CCA therapy.
\end{abstract}

Keywords: Hypoxia - chloroquine - EMT - metastasis - cholangiocarcinoma

Asian Pac J Cancer Prev, 16 (5), 2031-2035

\section{Introduction}

Cholangiocarcinoma (CCA) is an aggressive tumor with high infiltrating growth and metastasis to lymph node and blood vessels in humans as well as in an animal (Blechacz and Gores, 2008; Songserm et al., 2009; Sripa et al., 2011). CCA patients are predominantly clinically silent and difficult to diagnose until the disease has reached an advanced or metastatic stage, at which the prognosis is poor. Moreover, CCA exerts a poor response to current therapies (Thongprasert, 2005).

Hypoxia, a common hallmark of most solid tumors, is known to induce a transcription factor namely, hypoxia inducible factor, HIF-1 $\alpha$ (O'Donnell et al., 2006). In normal atmosphere, HIF- $1 \alpha$ is rapidly degraded by hydroxylation of prolyl hydroxylases domain proteins (PHDs) in the PHD-pVHL system (Fan et al., 2014). Under hypoxic conditions, the PHDs process is inhibited, the stabilization of HIF- $1 \alpha$ accumulates in the nucleus and dimerises with HIF-1 $\beta$ (Zhang et al., 2013), resulting in the activation of various target hypoxia-responsive genes controlling tumor progression, angiogenesis, invasion, metastasis and resistance to chemotherapy (Liu et al., 2008; Sahlgren et al., 2008). One impact of HIF-1 $\alpha$ 's target genes is a vascular endothelial growth factor (VEGF), that functions to increase $\mathrm{O}_{2}$ delivery to cells by stimulating angiogenesis, and intracellular proteins which allow cells to survive in $\mathrm{O}_{2}$ deprivation by reprogramming their metabolism (Semenza, 2012). Cobalt chloride $\left(\mathrm{CoCl}_{2}\right)$ is a chemically induced hypoxic-mimicking condition which occurs by inhibiting PHD and stabilizing HIF-1 $\alpha$, and it is frequently used for inducing a hypoxic condition in many in vitro systems (Yuan et al., 2003; Wu and Yotnda, 2011). It has been showed that $100 \mu \mathrm{M}$ of $\mathrm{CoCl}_{2}$ treatments to human prostate cancer cell lines resulted in elevated VEGF mRNA and protein secretion, and drove cells to be highly invasive metastatic phenotype (Liu et al., 1999). In addition, a recent study has demonstrated that CCA cells treated with $100 \mu \mathrm{M}$ of $\mathrm{CoCl}_{2}$ increased HIF-1 $\alpha$ expression that contributed to the progression by metastatic potential (Thongchot et al., 2014). The hypoxic microenvironment is very important in regulating tumor processes such as epithelial-mesenchymal transition (EMT) that is believed to be a major mechanism by which cancer cells become metastatic and invasive (Zhang et al., 2013). Hypoxia stabilizes HIF-1 $\alpha$ expression that induces EMT by induction of the mesenchymal markers $\mathrm{N}$-cadherin (Yang et al., 2007) and downregulation of the epithelial marker E-cadherin (Salnikov et al., 2012).

Chloroquine, 7-chloro-4 [4diethylamino1methyl butylamino] quinoline (CQ), is a widely well-known medicine used as a potent treatment of malaria and auto-

${ }^{I}$ Department of Biochemistry, ${ }^{3}$ Liver Fluke and Cholangiocarcinoma Research Center, Faculty of Medicine, ${ }^{2}$ Department of Biochemistry, Faculty of Associated Medical Sciences, Khon Kaen University, Khon Kaen, Thailand *For correspondence: nisana@kku.ac.th 
Suyanee Thongchot et al

immune diseases. Recently, several studies have shown that it has extensive biological effects such as inhibiting cell growth and/or inducing cell death in many types of cancer cells (Fan et al., 2006). Although CQ has been shown to inhibit metastasis of breast cancer cells to lung in a xenograft model (Jiang et al., 2010), the mechanism by which CQ suppresses tumor metastasis is still unclear.

In the present study, we investigated the in vitro effect of CQ on CCA cell metastasis under hypoxic-mimicking conditions. Expressions of HIF-1 $\alpha$, PHDs, VEGF, E-cadherin and $\mathrm{N}$-cadherin were determined in CQ treated CCA cells under hypoxia-mediated metastasis.

\section{Materials and Methods}

\section{Cell lines, chemicals, and reagents}

Two human CCA cell lines, M139 and M214, which were established at the Liver Fluke and Cholangiocarcinoma Research Center, Khon Kaen University, Thailand, were cultured in Ham's F-12 medium supplemented with 44 $\mathrm{mM} \mathrm{NaHCO}$, penicillin (100 units/ml), streptomycin $(100 \mathrm{mg} / \mathrm{ml})$ and $10 \%$ fetal bovine serum in a humidified atmosphere containing $5 \% \mathrm{CO}_{2}$. Cobalt chloride $\left(\mathrm{CoCl}_{2}\right)$, and chloroquine (CQ) were purchased from Sigma, St. Louis, MO, United States. All other chemicals used were of analytical grade.

\section{The in vitro cellular transwell migration assay}

A total of $4 \times 10^{4} \mathrm{CoCl}_{2}$ or CQ-treated cells were seeded onto the upper chamber of Transwell ${ }^{\circledR}(8 \mu \mathrm{m}$ pore size; Corning, NY, USA), and HAM's F-12 medium supplemented with $10 \%$ (v/v) FBS was placed in the lower chamber. After incubation at $37^{\circ} \mathrm{C}$ for 16 or $36 \mathrm{~h}$, cells in the upper surface of the filter were scraped off, and cells which migrated to the underside of the filter were fixed with absolute ethanol for $30 \mathrm{~min}$, stained with hematoxylin solution, and then counted under a microscope. The mean value of all low-power fields (200x) was determined. Assays were done in triplicate and three independent experiments were conducted.

\section{Western blot analysis}

Cells were washed with 1x PBS buffer and then lyzed with radioimmuno-precipitation assay (RIPA) buffer containing protease $\mathrm{K}$ inhibitor cocktail, $0.5 \mathrm{M} \mathrm{NaF}, 0.2 \mathrm{M}$ $\mathrm{NaVO}_{4}, 1 \mathrm{M}$ Tris-HCl pH 7.5, 0.5 M EDTA, 2.5 M NaCl, $10 \%$ NP-40, $10 \%$ SDS, triton X-100 and deionized water. Ten $\mu \mathrm{g}$ of protein lysates were electrophoresed in $10 \%$ or $12 \%$ sodium dodecyl sulfate (SDS)-polyacrylamide gel and transferred to a polyvinylidene fluoride membrane (Whatman, Dassel, Germany). Membranes were incubated with $10 \%$ skim milk to block any nonspecific binding. Then, membranes were incubated with primary antibodies against HIF-1 $\alpha$, PHD, E-cadherin, N-cadherin, and VEGF (1:200, 1:2,000, 1:2,000, 1:500 and 1:1,000 respectively; Abcam; MA, USA) overnight at $4^{\circ} \mathrm{C}$, followed by secondary antibodies at room temperature for $1 \mathrm{~h}$. Immunoreactive materials were developed by Enhanced Chemiluminescence Plus solution (GE Healthcare, Buckinghamshire, UK).

\section{Statistical analysis}

Data were presented as the means \pm standard deviation of three separate experiments. Statistical significance of the differences between the experimental conditions was determined by the SPSS version 17.0 (SPSS Inc., Chicago, IL) and was analyzed using unpaired, two-tailed student's t-test. Data were considered statistically significant when $\mathrm{p}<0.05(*)$ and $\mathrm{p}<0.001(* *)$.

\section{Results}

$C Q$ suppressed CCA cell migration under the $\mathrm{CoCl}_{2}-$ induced hypoxia

Recent studies have demonstrated that the behavior of CCA cell lines is significantly affected by hypoxia (Seubwai et al., 2012; Thongchot et al., 2014). We applied $100 \mu \mathrm{M} \mathrm{CoCl}_{2}$ to provide the hypoxic-mimic conditions for CCA cell culture, and trans-migrating cells were evaluated. Upon $\mathrm{CoCl}_{2}$ treatment for $36 \mathrm{~h}$ in $\mathrm{M} 139$ cells and $16 \mathrm{~h}$ in M214 cells, the results showed that cell migration was $59 \%$ increased $(\mathrm{p}=0.030)$ in M139 cells (Figure 1A), and 65\% increased ( $\mathrm{p}=0.043$ ) in M214 cells (Figure 1B) over the untreated cells.

To elucidate the anti-metastasis effects of CQ on CCA cell lines, the M139 and M214 cell lines were exposed to $50 \mu \mathrm{M}$ CQ (or not) under $100 \mu \mathrm{M} \mathrm{CoCl}_{2}$ and the transmigration assay was determined. The result showed that $50 \mu \mathrm{M}$ CQ treatment significantly suppressed the number of migrating cells when compared with untreated control cells (6.3 times for M319 cells in Figure 1A and 2.9 times for M214 cells in Figure 1B). The inhibitory effect of CQ on cell migration was markedly enhanced in $100 \mu \mathrm{M}$ $\mathrm{CoCl}_{2}$ treatment condition when compared with $\mathrm{CoCl}_{2}$

\section{A}

M139

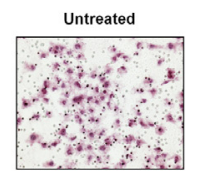

$50 \mu \mathrm{M} \mathrm{CQ}$
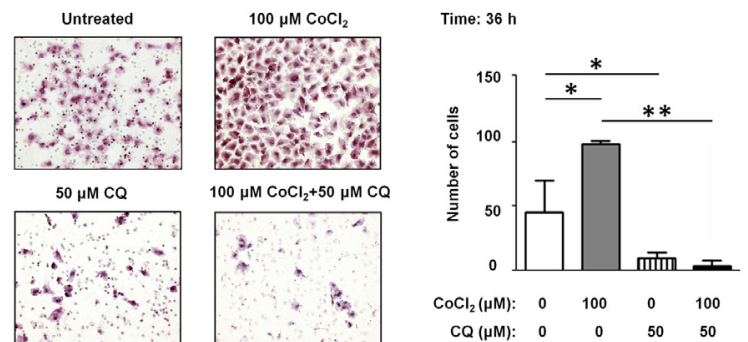

B
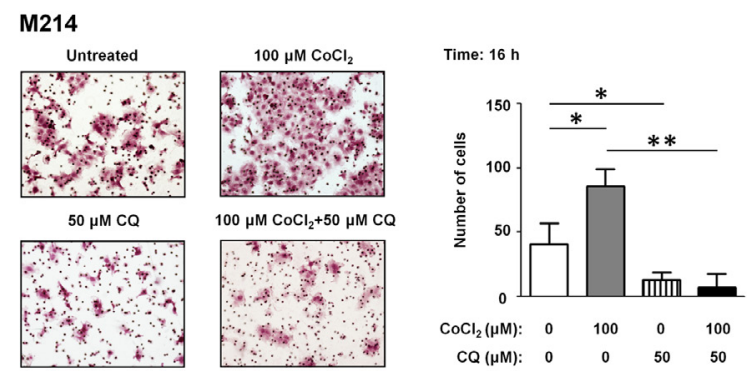

Figure 1. Effect of Hypoxia and CQ on in vitro M139 and M214 CCA Cells Migration; A transwell migration assay without matrigel was used to detect the migration activity of M139 and M214 CCA cells in the exposed to $50 \mu \mathrm{M}$ CQ (or not) under $100 \mu \mathrm{M}$ of $\mathrm{CoCl}_{2}$. Means $\pm \mathrm{SEM}$. $* \mathrm{P}<0.05$ and ** $\mathrm{p}<0.001$. Results are expressed as the means $\pm \mathrm{SD}$ error of the mean of three separated experiments 


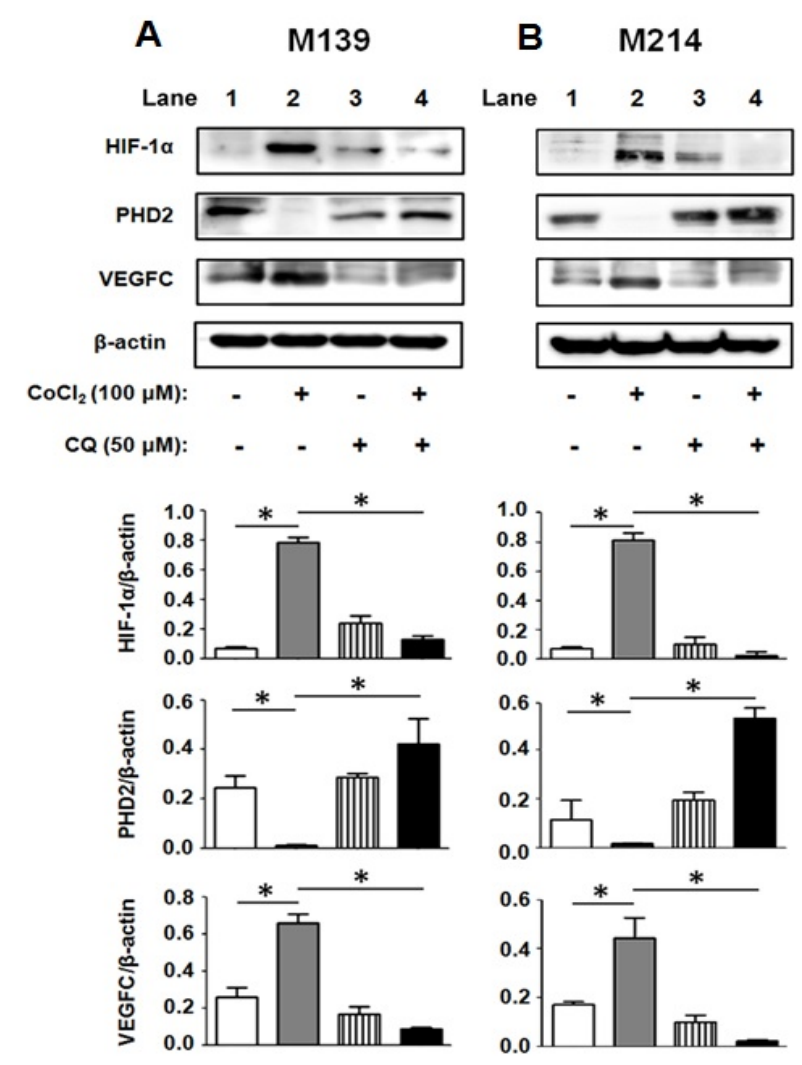

Figure 2. Western Blot Analysis of the Expression of HIF-1 $\alpha$, PHD-2, and VEGF in Each Group Treated in in vitro M139 and M214 CCA Cell Lines; Representative HIF-1 $\alpha$, PHD-2, and VEGF expression. Western blotting images are shown of CCA with untreated (Lane 1), $100 \mu \mathrm{M}$ of $\mathrm{CoCl}_{2}$ treatment (lane 2), $50 \mu \mathrm{M}$ of CQ treatment (lane 3), and $100 \mu \mathrm{M}$ of $\mathrm{CoCl}_{2}$ with CQ $50 \mu \mathrm{M}$ treatment (lane 4). Data are expressed as ratio of all proteins to $\beta$-actin, and are means \pm SD. ${ }^{*} \mathrm{p}<0.05$ and $* * \mathrm{p}<0.001$

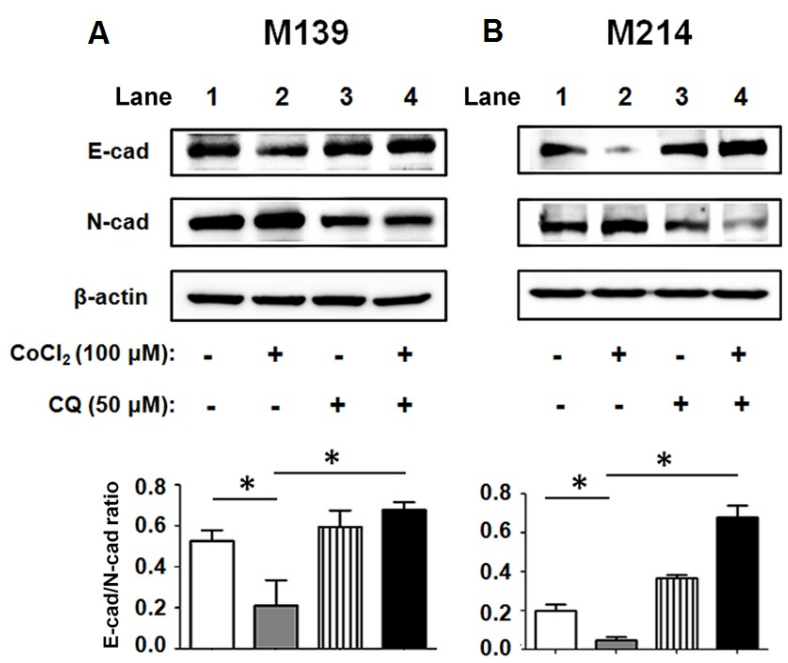

Figure 3. Western Blot Analysis of the Expression of HIF-1 $\alpha$, PHD-2, VEGF and EN Switch in Each Group Treated in in vitro M139 and M214 CCA Cell Line; Representative EN switch expression. Western blotting images are shown of CCA with untreated (Lane 1), $100 \mu \mathrm{M}$ of $\mathrm{CoCl}_{2}$ treatment (lane 2), $50 \mu \mathrm{M}$ of CQ treatment (lane 3), and $100 \mu \mathrm{M}$ of $\mathrm{CoCl}_{2}$ with CQ $50 \mu \mathrm{M}$ treatment (lane 4). Data are expressed as ratio of all proteins to $\beta$-actin, and are means \pm SEM. ${ }^{*} p<0.05$ and $* * \mathrm{p}<0.001$ treated alone (16.7 times in M319 and 14.3 times in M214 cells) and with CQ treated alone (1.7 times in M319 and 2.3 times in M214 cells) (Figure 1 A and Figure 1B).

$C Q$ altered the expression levels of metastasis-related proteins under $\mathrm{CoCl}_{2}$-induced hypoxia in CCA cells

M139 and M214 cells were treated with $\mathrm{CoCl}_{2}$ to induce hypoxia-mimicking conditions and the hypoxicresponsive proteins were assessed. The results revealed that $100 \mu \mathrm{M} \mathrm{CoCl}_{2}$ increased the expression of HIF-1 $1 \alpha$ but completely suppressed the PHD-2 protein level (lane 2 in Figure 2A for M139 and Figure 2B for M214 cells). The VEGF expression was significantly elevated under the $\mathrm{CoCl}_{2}$ treatment in M139 (lane 2 in Figure 2A) and M214 (lane 2 in Figure 2B) cells over the untreated control cells. The CCA cells treated with $50 \mu \mathrm{M}$ CQ showed the suppression of protein levels of HIF-1 $\alpha$ and VEGF when compared with untreated cells (lane 3 in Figure 2A for M139 and Figure 2B for M214). Cells treated with $50 \mu \mathrm{M}$ CQ combined with $100 \mu \mathrm{M} \mathrm{CoCl}_{2}$ continued to suppress HIF-1 $\alpha$ and VEGF but induce PHD-2 when compared with cells treated with $\mathrm{CoCl}_{2}$ alone (lane 4 in Fig. $2 \mathrm{~A}$ for M139 and Fig. 2B for M214 cells). Notably, CQ alone did not suppress the level of PHD-2 in both cells (lane 3 in Figure 2A for M139 and Figure 2B for M214).

Our results showed that treatment of $100 \mu \mathrm{M} \mathrm{CoCl}_{2}$ reduced the ratio between $\mathrm{E}$-cadherin and $\mathrm{N}$-cadherin in CCA cells (lane 2 in Figure 3A for M139 and Fig. 3B for M214 cells). Interestingly, $50 \mu \mathrm{M}$ CQ applied in CCA cells increased the ratio between E-cadherin and $\mathrm{N}$-cadherin (lane 3 in Figure 3A for M139 and Figure 3B for M214). Cells treated with $50 \mu \mathrm{M}$ CQ combined with $100 \mu \mathrm{M}$ $\mathrm{CoCl}_{2}$ also increased in the ratio between E-cadherin and $\mathrm{N}$-cadherin when compared with cells treated with $\mathrm{CoCl}_{2}$ alone (lane 4 in Figure 3A for M139 and Figure 3B for M214 cells).

\section{Discussion}

From accumulating evidence hypoxia has emerged as a pivotal factor of tumor development since it can activate the related genes of the tumor cells in order to adapt to the microenvironment to promote tumor metastatic progression and resistance to therapy (Vaupel and Mayer, 2007). Metastasis is the most lethal characteristic of CCA and it is a major problem in CCA treatment. Elucidation of molecular mechanisms that are involved in metastasis is still a challenge for developing new effective therapeutic drugs and improving the clinical outcome of patients with CCA. This experimental study points to a fundamental effect of CQ on CCA cell metastasis under hypoxiamimicking condition. We created an in vitro hypoxia-like state by treatment of two CCA cell lines with $100 \mu \mathrm{M}$ of $\mathrm{CoCl}_{2}$ (Liu et al., 1999; Law et al., 2012; Thongchot et al., 2014). We demonstrated that $\mathrm{CoCl}_{2}$-induced hypoxia significantly increased metastases in both CCA cell lines, using a transwell migration assay. We also confirmed that $\mathrm{CoCl}_{2}$ truly induces hypoxic conditions as demonstrated by the suppressing the protein level of PHD-2 and the increased level of hypoxia responsive elements HIF$1 \alpha$ and VEGF (Wu and Yotnda, 2011). In addition, we 
revealed that $\mathrm{CoCl}_{2}$-induced hypoxia facilitates $\mathrm{CCA}$ cells to metastasize by altering the level of proteins involved in EMT-mediated metastasis, i.e., reduction of E-cadherin to N-cadherin ratio, a hallmark of EMT (Gravdal et al., 2007; Chen et al., 2014) were observed for M139 and M214 cells. Our study suggests that the HIF-1 $\alpha /$ VEGF/ EMT is likely to play a critical role in the metastatic potential in CCA.

Chloroquine (CQ) is a well-tolerated, safe drug which is already in clinical use for treatment of malaria and other types of parasitic infections (Winstanley, 2003). Our results showed that CQ $(50 \mu \mathrm{M})$ significantly delayed CCA cell migration and completely inhibited the effect of $\mathrm{CoCl}_{2}$ enhanced metastasis by suppressing the protein levels of HIF-1 $\alpha$. Interestingly, we also demonstrated that CQ stabilized the protein level of the HIF- $1 \alpha$ inhibitor PHD-2 in CCA cells under hypoxic condition. Consequently, the reduction of HIF-1 $\alpha$ potentially leads to a decrease in VEGF expression, resulting in metastasis suppression. Although CQ has been reported to inhibit tumor cell growth, it also inhibits tumor metastasis which has been previously demonstrated in breast cancer cells by suppressing matrix metalloproteinase (MMP-2 and MMP 9) mRNA expression and protein activities (Tuomela et al., 2013). Interestingly, our results showed that CQ disrupted EMT-mediated hypoxia in CCA cells by reducing $\mathrm{N}$-cadherin but induced $\mathrm{E}$-cadherin upon $\mathrm{CoCl}_{2}$ treatment. To gain further knowledge of the mechanisms by which CQ inhibit EMT-mediated metastasis in CCA needs to be further investigated.

In conclusion, our study supports the role of hypoxia that induces tumor metastasis, possibly mediated by EMT and CQ which can inhibit CCA metastasis.

\section{Acknowledgements}

This work was supported by the Higher Education Research Promotion and National Research University Project of Thailand, Office of the Higher Education Commission, through the Center of Excellence in Specific Health Problems in Greater Mekong Sub-region cluster (SHeP-GMS), Khon Kaen University to ST and NN, Cholangiocarcinoma Screening and Care Program (CASCAP), Khon Kaen University, Thailand and a MidCareer Grant (RSA5280007), Thailand Research Fund to NN. We would like to acknowledge Professor Ross Andrews, for editing the MS via Publication Clinic KKU, Thailand.

\section{References}

Blechacz B, Gores GJ (2008). Cholangiocarcinoma: advances in pathogenesis, diagnosis, and treatment. Hepatology, $\mathbf{4 8 ,}$ 308-21.

Chen J, Zhao J, Ma R, et al (2014). Prognostic significance of E-cadherin expression in hepatocellular carcinoma: a metaanalysis. PloS One, 9, 103952.

Fan C, Wang W, Zhao B, et al (2006). Chloroquine inhibits cell growth and induces cell death in A549 lung cancer cells. Bioorg Med Chem, 14, 3218-22.

Fan L, Li J, Yu Z, et al (2014). The hypoxia-inducible factor pathway, prolyl hydroxylase domain protein inhibitors, and their roles in bone repair and regeneration. Biomed Res Int, 2014, 239356.

Gravdal K, Halvorsen OJ, Haukaas SA, et al (2007). A switch from $\mathrm{E}$-cadherin to $\mathrm{N}$-cadherin expression indicates epithelial to mesenchymal transition and is of strong and independent importance for the progress of prostate cancer. Clin Cancer Res, 13, 7003-11.

Jiang P-D, Zhao Y-L, Deng X-Q, et al (2010). Antitumor and antimetastatic activities of chloroquine diphosphate in a murine model of breast cancer. Biomed Pharmacother, 64, 609-14.

Law P-C, Auyeung KK, Chan L-Y, et al (2012). Astragalus saponins downregulate vascular endothelial growth factor under cobalt chloride-stimulated hypoxia in colon cancer cells. BMC Complement Altern Med, 12, 160.

Liu L, Ning X, Sun L, et al (2008). Hypoxia-inducible factor-1 $\alpha$ contributes to hypoxia-induced chemoresistance in gastric cancer. Cancer Sci, 99, 121-8.

Liu X-H, Kirschenbaum A, Yao S, et al (1999). Upregulation of vascular endothelial growth factor by cobalt chloridesimulated hypoxia is mediated by persistent induction of cyclooxygenase- 2 in a metastatic human prostate cancer cell line. Clin Exp Metastasis, 17, 687-94.

O'Donnell JL, Joyce MR, Shannon AM, et al (2006). Oncological implications of hypoxia inducible factor- $1 \alpha$ (HIF-1 $\alpha$ ) expression. Cancer Treat Rev, 32, 407-16.

Sahlgren C, Gustafsson MV, Jin S, et al (2008). Notch signaling mediates hypoxia-induced tumor cell migration and invasion. Proc Natl Acad Sci USA, 105, 6392-7.

Salnikov AV, Liu L, Platen M, et al (2012). Hypoxia induces EMT in low and highly aggressive pancreatic tumor cells but only cells with cancer stem cell characteristics acquire pronounced migratory potential. PloS One, 7, 46391.

Semenza GL (2012). Molecular mechanisms mediating metastasis of hypoxic breast cancer cells. Trends Mol Med, 18, 534-43.

Seubwai W, Kraiklang R, Wongkham C, et al (2012). Hypoxia enhances aggressiveness of cholangiocarcinoma cells. Asian Pac J Cancer Prev, 13, 53-8.

Songserm N, Prasongwattana J, Sithithaworn P, et al (2009). Cholangiocarcinoma in experimental hamsters with longstanding Opisthorchis viverrini infection. Asian Pac J Cancer Prev, 10, 299-302.

Sripa B, Bethony JM, Sithithaworn P, et al (2011). Opisthorchiasis and Opisthorchis-associated cholangiocarcinoma in Thailand and Laos. Acta Trop, 120, 158-68.

Thongchot S, Yongvanit P, Loilome W, et al (2014). High Expression of HIF-1 $\alpha$, BNIP3 and PI3KC3: hypoxiainduced autophagy predicts cholangiocarcinoma survival and metastasis. Asian Pac J Cancer Prev, 15, 5873-8.

Thongprasert S (2005). The role of chemotherapy in cholangiocarcinoma. Ann Oncol, 16, 93-6.

Tuomela J, Sandholm J, Kauppila JH, et al (2013). Chloroquine has tumor-inhibitory and tumor-promoting effects in triple-negative breast cancer. Oncol Lett, 6, 1665-72.

Vaupel P, Mayer A (2007). Hypoxia in cancer: significance and impact on clinical outcome. Cancer Metastasis Rev, 26, 225-39.

Winstanley P (2003). The contribution of clinical pharmacology to antimalarial drug discovery and development. Br J Clin Pharmacol, 55, 464-8.

Wu D, Yotnda P (2011). Induction and testing of hypoxia in cell culture. J Vis Exp, 12, 2899.

Yang Z, Zhang X, Gang H, et al (2007). Up-regulation of gastric cancer cell invasion by Twist is accompanied by N-cadherin and fibronectin expression. Biochem Biophys Res Commun, 358, 925-30. 
Yuan Y, Hilliard G, Ferguson T, et al (2003). Cobalt inhibits the interaction between hypoxia-inducible factor-alpha and von hippel-lindau protein by direct binding to hypoxia-inducible factor-alpha. J Biol Chem, 278, 15911-6.

Zhang L, Huang G, Li X, et al (2013). Hypoxia induces epithelial-mesenchymal transition via activation of SNAI1 by hypoxia-inducible factor- $1 \alpha$ in hepatocellular carcinoma. BMC Cancer, 13, 108. 